\title{
Impact of Socio-Economic Dynamics of Teachers on English Language Performance in Sri Lankan Schools: Mediating Influence of School Social Status
}

\author{
Dr. Viruli A. de Silva ${ }^{1}$ \\ Dr. Hemamali Palihakkara² \\ AHEAD SL Cell, Saegis Campus, Nugegoda, Sri Lanka 1 \& 2
}

\begin{abstract}
This systematic and scientific study bridged a few identified research gaps in extent literature, on improving English Language Performance (ELP) in schools, using empirical evidence from Sri Lanka. The strong affiliation of English language competence with social and economic power, especially with youth employability, in the context of globalization had warranted an urgent need. Globally, researchers have explored the influence of various factors of stakeholders on ELP in Schools, but the influence of socio-economic factors of teachers on ELP in public schools and the mediating influence of 'school social status' on this relationship yet to be examined. This cross-sectional study had a mixed methods approach. Used quantitative and qualitative techniques for primary data collection through a field study. Secondary data were collected through published documents from reliable sources. The impact of three teacher socio-economic dynamics: (i) English proficiency, (ii) motivation and (iii) training on ELP in public schools were examined, through the mediator 'school social status.' A random sample of six schools from three different categories in the Colombo Zone, Western Province were selected. The three socio-economic dynamics: English proficiency, motivation and training of teachers showed a significant and positive influence on improving the ELP of public schools in Sri Lanka, and the 'school social status' significantly mediated this relationship. The originality of the study and implications for policy makers to improve ELP in Sri Lankan public schools were discussed.
\end{abstract}

Keywords: Socio-economic factors, School Category, Mediators, Improving Standards 